\title{
Self-Compassion: An Alternative Conceptualization of a Healthy Attitude Toward Oneself
}

\author{
KRISTIN NEFF \\ University of Texas at Austin, \\ Austin, Texas, USA
}

\begin{abstract}
This article defines and examines the construct of self-compassion. Self-compassion entails three main components: (a) self-kindness-being kind and understanding toward oneself in instances of pain or failure rather than being harshly self-critical, (b) common humanity - perceiving one's experiences as part of the larger human experience rather than seeing them as separating and isolating, and (c) mindfulness - holding painful thoughts and feelings in balanced awareness rather than over-identifying with them. Self-compassion is an emotionally positive selfattitude that should protect against the negative consequences of self-judgment, isolation, and rumination (such as depression). Because of its non-evaluative and interconnected nature, it should also counter the tendencies towards narcissism, selfcenteredness, and downward social comparison that have been associated with attempts to maintain self-esteem. The relation of self-compassion to other psychological constructs is examined, its links to psychological functioning are explored, and potential group differences in self-compassion are discussed.
\end{abstract}

In recent years, several criticisms have been made of the use of self-esteem as a primary measure of psychological health (Baumeister, Smart, \& Boden, 1996; Damon, 1995; Ellis \& London, 1993; Finn, 1990; Hewitt, 1998; McMillan, Singh, \& Simonetta, 1994; Seligman, 1995; Swann, 1996). Self-esteem, which stems from evaluations of self-worth, is constituted by judgments and comparisons (Coopersmith, 1967; Harter, 1999). As William James (1890) proposed over a century ago, self-esteem involves evaluating personal performances (how good am I?) in comparison to set standards (what counts as good enough?) in domains of perceived importance (it's important to be good at this). Self-esteem also involves looking to others' evaluations of the self (how much do others like me, approve of me?), in order to determine how much one likes the self (Cooley, 1902; Mead, 1934). Social comparison is an additional determinant of self-esteem (Aspinwall \& Taylor, 1993; Beach \& Tesser, 1995; Buunk, 1998; Deci \& Ryan, 1995; Suls \& Wills, 1991), so that the self is evaluated in relation to the performances of others.

The psychological benefits of high self-esteem have been widely extolled in both academia and the popular press (Branden, 1969; Coopersmith, 1967; McKay

Received 25 February 2002; accepted 19 August 2002.

The author gratefully acknowledges Stephanie Rude, Frank Richardson, and Rupert Isaacson for their support and guidance while the ideas for this article were being developed, and for their helpful comments on earlier versions of this manuscript.

Address Correspondence to Kristin Neff, Department of Educational Psychology, George Sanchez Building 504, University of Texas, Austin, Texas, 78712-1296. E-mail: kristin.neff@mail.utexas.edu 
\& Fanning, 1987; Rosenberg, 1979; Steinhem, 1992)—leading many schools to adopt large-scale programs to enhance students' self-esteem (e.g., the California Task Force to Promote Self-Esteem). While there is little doubt that low self-esteem is linked to a host of negative psychological outcomes, such as lack of motivation, depression, and suicidal ideation (see Harter, 1999, for a review), it is less clear that raising people's self-esteem is the panacea it is often made out to be. First, it is difficult to raise an individual's self-esteem, since self-esteem has proven to be highly resistant to change (Swann, 1996). Moreover, even high self-esteem may have negative corollaries. Some psychologists argue that an over-emphasis on evaluating and liking the self may lead to narcissism, self-absorption, self-centeredness, and a lack of concern for others (Damon, 1995; Seligman, 1995). Attempts to protect or enhance self-esteem may also cause distortions in self-knowledge (Baumeister, Heatherton, \& Tice, 1993; Sedikides, 1993; Taylor \& Brown, 1988), making it difficult to identify areas in which change or growth is needed. The desire for high selfesteem may result in a willingness to see the worst in others as a means of rating the self more favorably in comparison (Crocker, Thompson, McGraw, \& Ingerman, 1987; Feather, 1994), and in fact, high rather than low self-esteem has been associated with increased prejudice toward out-groups (Aberson, Healy, \& Romero, 2000; Allport, 1954; Turner, Hogg, Oakes, Reicher, \& Wetherell, 1987). Finally, as Baumeister et al. (1996) have argued, an inflated sense of self-esteem may lead to aggression and violence against those perceived to threaten the ego.

For these reasons, several psychologists have tried to introduce alternative conceptualizations of a healthy attitude and relationship to oneself, such as selfrespect (Seligman, 1995), self-efficacy (Bandura, 1990), true self-esteem (Deci \& Ryan, 1995), or personal character (Damon, 1995). Another useful alternative may be found by drawing upon an important concept in Buddhist philosophy - selfcompassion (Bennett-Goleman, 2001; Brown, 1999; Hanh, 1997; Kornfield, 1993; Rosenberg, 2000; Rutledge, 1997; Salzberg, 1997; Wallace, 1999). While the concept of self-compassion has existed in Eastern philosophical thought for centuries, it is a relatively new concept for Western psychology (though it is related to other Western psychological concepts, a point that will be taken up shortly). The past decade has seen an increasing interchange of ideas between Buddhism and psychology (Epstein, 1995; Molino, 1998; Nisker, 1998; Rubin, 1996; Watson, Batchelor, \& Claxton, 1999), broadening our existing understanding of mental well-being and leading to new ways of researching and treating mental disorders (e.g., Kabat-Zinn's mindfulness-based stress-reduction programs; Kabat-Zinn \& Chapman-Waldrop, 1988; Kabat-Zinn, Massion, Kristeller \& Peterson, 1992). This article represents an attempt to add to this dialogue by examining how the concept of self-compassion might expand our current understandings of healthy self-attitudes. Its goal is to clearly define what the process of giving oneself compassion entails, and to explore the potential relationship of self-compassion to other aspects of psychological functioning. Because little research has been conducted on self-compassion, ${ }^{1}$ the discussion will be based on theory rather than empirical findings. Still, a theoretical understanding of self-compassion should be highly relevant for researchers in a variety of academic disciplines interested in self and identity issues.

\section{What Is Self-Compassion?}

The definition of "self-compassion" is related to the more general definition of "compassion." Compassion involves being touched by the suffering of others, 
opening one's awareness to others' pain and not avoiding or disconnecting from it, so that feelings of kindness toward others and the desire to alleviate their suffering emerge (Wispe, 1991). It also involves offering nonjudgmental understanding to those who fail or do wrong, so that their actions and behaviors are seen in the context of shared human fallibility. Self-compassion, therefore, involves being touched by and open to one's own suffering, not avoiding or disconnecting from it, generating the desire to alleviate one's suffering and to heal oneself with kindness. Self-compassion also involves offering nonjudgmental understanding to one's pain, inadequacies and failures, so that one's experience is seen as part of the larger human experience.

While many psychological theories assume that individuals are primarily selfinterested, having more concern for themselves than for others (see Miller, 1999, for a review), common experience suggests people are often much harsher and unkind toward themselves than they ever would be to others they cared about, or even to strangers. While such severity toward oneself may sometimes stem from a fear of egotism, self-indulgence, or self-centeredness (Rubin, 1975), being compassionate toward oneself does not entail being self-centered. Instead, self-compassion tends to enhance feelings of compassion and concern for others. Self-compassion entails seeing one's own experience in light of the common human experience, acknowledging that suffering, failure, and inadequacies are part of the human condition, and that all people - oneself included - are worthy of compassion. Less judgment of oneself also allows for less judgment of others, as comparisons between oneself and others are not needed to enhance or defend self-esteem. Compassion is not extended to oneself because one is superior or more deserving than others, rather, it is done precisely because the individual recognizes his or her interconnectedness and equality with others (Brown, 1999). Thus, feeling compassion for oneself is similar to feeling forgiveness for oneself. Enright remarks that when we forgive, "we welcome the other into the human community; we see each other as equally worthy of respect" (Enright, Freedman, \& Rique, 1998, p. 49.) Likewise, having self-compassion entails forgiving one's failings and foibles, respecting oneself as a fully human-and therefore limited and imperfect-being.

Some may fear that having too much self-compassion leads to passivity, but this should not be the case when feelings of self-compassion are genuine. While having self-compassion requires that one does not harshly criticize the self for failing to meet ideal standards, it does not mean that one's failings go unnoticed or unrectified. Rather, it means that the actions needed for optimal functioning and health (and having compassion for oneself means that one desires well-being for oneself) are encouraged with gentleness and patience. Thus, self-compassion should not imply passivity or inaction with regard to weaknesses observed in the self. Rather, it is the lack of self-compassion that is more likely to lead to passivity. When the self is harshly judged for its failings in the belief that self-flagellation will somehow force change and improvement, the protective functions of the ego will often act to screen inadequacies from self-awareness so that one's self-esteem is not threatened (Horney, 1950; Reich, 1949). Without self-awareness, these weaknesses will remain unchallenged. By giving compassion to oneself, however, one provides the emotional safety needed to see the self clearly without fear of self-condemnation, allowing the individual to more accurately perceive and rectify maladaptive patterns of thought, feeling and behavior (Brown, 1999). Moreover, the care intrinsic to compassion should provide a powerful motivating force for growth and change. For example, parents with compassion for their children do not allow their children to harm 
themselves, and may impose unpleasant requirements or restrictions on their children in order to encourage their healthy development. The compassionate parents' actions are not judgmental or punitive, but are infused with kindness, love, and concern for their children's well-being. Similarly, having compassion for oneself often entails giving up harmful behaviors to which one is attached, and encouraging oneself to take whatever actions are needed - even if painful or difficult - in order to further one's well-being.

It should also be noted that self-compassion is quite distinct from self-pity (Goldstein \& Kornfield, 1987). When individuals feel pity for others they typically feel highly separate and disconnected from them ("thank goodness it's your problem not mine"), while in the case of compassion individuals feel connected to others and are aware that suffering is something all humans experience ("there but for fortune go I"). Similarly, when individuals feel self-pity, they become immersed in their own problems and forget that others have similar problems. They ignore their interconnections with others, and instead feel that they are the only ones in the world who are suffering. Self-pity tends to emphasize egocentric feelings of separation from others and exaggerate the extent of personal suffering. Self-compassion, on the other hand, allows one to see the related experiences of self and other without this type of distortion or disconnection.

Another way in which self-compassion is distinct from self-pity concerns the extent to which individuals are identified with their own pain and suffering. While experiencing self-pity, individuals typically become carried away with, wrapped up in, completely absorbed by their own feelings. This process can be termed "over-identification," in that individuals become so immersed in their current emotional reactions that other aspects of the person-those capable of alternative emotional responses or mental interpretations, for example - are inaccessible (Bennett-Goleman, 2001). Because one's awareness is totally consumed by subjective reactions, one cannot step back from the situation and adopt a more objective perspective. In contrast, self-compassion requires that individuals do not overidentify with their emotions, so that there is "mental space" in which to extend oneself kindness and recognize the broader human context of one's experience (Goldstein \& Michaels, 1985; Scheff, 1981). At the same time, self-compassion requires that individuals do not avoid or repress their painful feelings, so that they are able to acknowledge and feel compassion for their experience in the first place. Thus, a compassionate attitude toward oneself requires the equilibrated mental perspective known as mindfulness (Bennett-Goleman, 2001; Epstein, 1995; Gunaratana, 1993; Hanh, 1976; Kabat-Zinn, 1994; Langer, 1989; Nisker, 1998; Rosenberg, 1999). Mindfulness is a balanced state of awareness that avoids the extremes of over-identification and disassociation with experience and entails the clear seeing and acceptance of mental and emotional phenomena as it arises. Martin (1997) writes that mindfulness is "a situation in which the sense of self or self-esteem maintenance softens or disappears" (p. 292), allowing for a nonjudgmental, receptive mind state in which one's thoughts and feelings are observed for what they are, not in terms of how they impact one's self-concept. Mindfulness is a spacious, flexible mindset that is not attached to any particular point of view (Langer, 1989), yielding greater insight into one's experience. In many ways, mindfulness is similar to the open, nonjudgmental attentional stance understood to facilitate therapist-client interactions, variously described as detachment (Bohart, 1993), decentering (Safran \& Segal, 1990), presence (Bugental, 1987), or evenly suspended attention (Freud, 1958), but in this case applied to one's own experience. 
When individuals are not being mindful of their painful thoughts and feelings, they are not accepting their experience for what it is, and this non-acceptance may manifest as the refusal to bring it into conscious awareness (Hayes, Wilson, Gifford, Follette, \& Strosahl, 1996), or else as intense emotional resistance to the pain, so that one is caught up and swept away by one's aversive reaction. This latter type of response typically involves narrowly focusing and ruminating on one's negative emotions (Nolen-Hoeksema, 1991). In the case of negative emotions associated with personal failure or inadequacies, there is an exaggerated focus on implications for self-worth (another way in which "over-identification" is occurring), leading to overly severe judgments and criticisms of the self. Over-identification magnifies feelings of separateness and isolation, as the sense of self is amplified and the awareness that all humans experience suffering and disappointment is obscured. Unfortunately, rumination, self-criticism and feelings of separation have been shown to be highly associated with maladaptive outcomes such as depression (Blatt, Quinlan, Chevron, McDonald \& Zuroff, 1982; Bowlby, 1980; Nolen-Hoeksema, 1991). In contrast, Hayes, Strosahl, and Wilson (1999) have found that mindfulness training can help prevent depression by encouraging individuals to accept and tolerate their painful thoughts and emotions rather than trying to change them, while simultaneously placing these thoughts and emotions in a larger context so that their significance is seen with greater perspective (also see the mindfulness-based therapy approach of Teasdale et al., 2000).

\section{The Three Faces of Self-Compassion}

In summary, when faced with experiences of suffering or personal failure, selfcompassion entails three basic components: (a) self-kindness - extending kindness and understanding to oneself rather than harsh judgment and self-criticism, (b) common humanity - seeing one's experiences as part of the larger human experience rather than seeing them as separating and isolating, and (c) mindfulness-holding one's painful thoughts and feelings in balanced awareness rather than over-identifying with them. While these aspects of self-compassion are conceptually distinct, and are experienced differently at the phenomenological level, they also interact so as to mutually enhance and engender one another. It has already been argued that a certain degree of mindfulness is needed in order to allow enough mental distance from one's negative experiences that feelings of self-kindness and common humanity can arise. However, mindfulness also makes a more direct contribution to the other two components. First, the nonjudgmental, detached stance of mindfulness lessens self-criticism and increases self-understanding (Jopling, 2000), thus directly enhancing self-kindness. Also, the balanced perspective-taking of mindfulness directly counters the egocentrism that causes feelings of isolation and separateness from the rest of humanity, thereby increasing feelings of interconnectedness (Elkind, 1969).

Moreover, self-kindness and feelings of connectedness can serve to further increase mindfulness. For example, if one stops judging and berating oneself long enough to experience a degree of self-acceptance, the negative impact of the emotional experience will be lessened, making it easier to maintain balanced awareness of one's thoughts and emotions (Fredrickson, 2001) - to neither run away from or run away with the feelings (Goldstein \& Kornfield, 1987). Similarly, remembering that suffering and personal failure happen to all people helps put one's experience into perspective, also enhancing the ability to be mindful of one's thoughts and emotions and to not over-identify with them. Finally, self-kindness and feelings of common 
humanity enhance one another as well. When the self is harshly judged, self-consciousness is strengthened and this heightened sense of self serves to increase feelings of isolation (Brown, 1999). However, kindness toward oneself softens this selfconsciousness, allowing for more feelings of interconnection (Fromm, 1963). Conversely, realizing that suffering and personal failures are shared with others lessens the degree of blame and judgment placed on oneself (Rubin, 1975), depersonalizing one's experience so that feelings of kindness and understanding are generated for all who are in pain, including oneself.

\section{Self-Compassion and Other Psychological Approaches}

While its origins are Eastern, the construct of self-compassion is consistent with the work of Western psychologists in a variety of disciplines. Due to space limitations, it is not possible to provide a comprehensive overview of the ways in which selfcompassion relates to other theory and research. However, some of the main areas of interrelation will be briefly discussed.

\section{The Self-in-Relation Model}

The closest resemblance to the self-compassion concept is probably found in the work of Judith Jordan, one of the founders of the self-in-relation model of women's psychological development (Jordan, 1997; Jordan, Kaplan, Miller, Stiver, \& Surrey, 1991). Jordan (1989, 1991a, 1991b) has written briefly about the concept of selfempathy in her writings (though the ideas have not been fully elaborated), describing it as a process in which the individual adopts an attitudinal stance of nonjudgment and openness toward the self. In this view, self-empathy is closely related to empathy for others, defined in terms of feeling emotionally connected to others and recognizing one's similarity to others, so that one empathizes with the inevitable failure and loss associated with being human (Jordan, 1989). Jordan writes that selfempathy is a kind of "corrective relational experience" with oneself in which previously judged and disowned aspects of self are "accepted and responded to in a caring, affectively present and re-connected manner" (1991b, p. 287). Thus, we can see that Jordan's definition of self-empathy implicitly touches on the three elements of self-compassion: self-kindness, common humanity, and mindfulness. Jordan primarily speaks of self-empathy as a process that emerges out of a mutually empathic therapy experience, and argues that self-empathy can lead to lasting structural change in self-representations and relational images in a way that greatly enhances psychological well-being. Unfortunately, very little work has been conducted in order to confirm, refine, or expand Jordan's views on self-empathy. ${ }^{2}$ Also, because it is couched in the language of women's development, Jordan's conceptualization of self-empathy runs the risk of being linked to a specifically female rather than a generally human experience of self and others.

\section{Humanistic Psychology}

The concept of self-compassion also resonates with the work of many humanistic psychologists (Ellis, 1973; Fromm, 1963; Maslow, 1954; Rogers, 1961). In Toward a Psychology of Being, for instance, Maslow (1968) stressed the importance of helping people to accept and acknowledge their own pain and failings as necessary for their growth. He argued that "the great cause of much psychological illness is the fear of 
knowledge of oneself-of one's emotions, impulses, memories, capacities, potentialities.... In general this kind of fear is defensive, in the sense that is a protection of our self-esteem" (p. 60). Encouraging others to have compassion for their own failings and suffering is one way to increase self-understanding, helping to foster what Maslow called "B-perception"-nonjudgmental, forgiving, loving acceptance of Being - toward oneself. In this way, self-compassion is comparable to what Rogers (1961) called "unconditional positive regard" toward oneself — not in the sense that one makes unconditionally positive judgments or evaluations of the self, but in the sense that one adopts an unconditionally caring emotional stance toward oneself. Rogers felt that a nonjudgmental, kind self-attitude was the ultimate goal of client-centered therapy, allowing an individual to become "more selfaware, more self-acceptant, more self-expressive, less defensive and more open... free to change and grow and move in the directions natural to the human organism" (Rogers \& Stevens, 1967, p. 55). Similarly, Snyder (1994) suggested that the goal of therapy is to help clients develop an "internal empathizer ... a primary attitude of curiosity and compassion towards one's own responses [to experience]" (p. 90). Finally, self-compassion provides the individual with what Ellis (1973) has termed "unconditional self-acceptance," in which the self's worth is not rated or evaluated but is assumed as an intrinsic aspect of existence, and directly fosters what Ellis believed was the key to psychological well-being: developing an attitude of tolerance for the uncertainties in life and acknowledging and forgiving one's own limitations.

Of course, humanistic psychology is not without its critics. In recent years, humanistic psychology (and much of modern psychology in general) has been faulted for being too individualistic - for over-emphasizing the need for autonomy, self-actualization, and self-fulfillment while not paying enough attention to equally important needs for relationship, community, and responsibility (Fancher, 1995; Pearson \& Podeschi, 1999; Richardson, Fowers, \& Guignon, 1999). The concept of self-compassion, however, which bases feelings of self-acceptance on a sense of shared humanity, does not separate self from others, and is therefore consistent with the humanistic value of self-acceptance without promoting an overly individualistic self-focus. Self-compassion also fosters a sense of social connectedness, and should therefore encourage rather than undermine feelings of responsibility to others.

\section{Emotional Regulation}

The construct of self-compassion is also relevant to recent work in the field of emotional development, specifically coping and emotional regulation (these terms are often used interchangeably; see Brenner \& Salovey, 1997). Emotional regulation refers to the processes by which individuals pay attention to their emotions, manage the intensity and duration of emotional arousal, and transform the nature and meaning of feeling states when faced with stressful or distressing situations (Thompson, 1994). Traditionally, emotion-focused coping has been viewed in terms of emotional avoidance (e.g., laughing things off as unimportant), so that emotional reactions to difficulties are seen as defense mechanisms used to deny or distract one's attention from problems rather than facing them directly (Lazarus, 1993). More recently, however, psychologists are recognizing that emotion-focused coping can also take a more productive, proactive form. Stanton and colleagues (Stanton, Danoff-Burg, Camron, \& Ellis, 1994; Stanton, Kirk, Cameron, \& Danoff-Burg, 2000) have shown that "emotional approach" coping strategies - in which individuals make effortful attempts to maintain awareness of, explore and understand 
their emotions - are related to positive psychological adjustment (see also Pennebaker, 1989, 1993). In many ways, self-compassion can be viewed as a useful emotional-approach coping strategy. Self-compassion requires mindful awareness of one's emotions (Bennett-Goleman, 2001; Kabat-Zinn, 1994; Kornfield, 1993; Salzberg, 1997), so that painful or distressing feelings are not avoided but are instead approached with kindness, understanding, and a sense of shared humanity. Thus, negative emotions are transformed into a more positive feeling state, allowing for the clearer apprehension of one's immediate situation and the adoption of actions that change oneself and/or the environment in appropriate and effective ways. For this reason, self-compassion may prove to be an important aspect of emotional intelligence, which involves the ability to monitor one's own emotions and to skillfully use this information to guide one's thinking and actions (Salovey \& Mayer, 1990).

\section{Self-Compassion versus Self-Esteem}

It appears that self-compassion may entail many of the psychological benefits that have been associated with self-esteem, but with fewer of its pitfalls. Self-compassion represents a positive emotional stance towards oneself, in that one extends feelings of kindness and caring toward oneself. It helps to motivate productive behavior and protect against the debilitating effects of self-judgment (Horney, 1950) such as depression and anxiety (Blatt et al., 1982). Self-compassion, however, is not based on the performance evaluations of self and others, or on congruence with ideal standards. In fact, self-compassion takes the entire self-evaluation process out of the picture, focusing on feelings of compassion toward oneself and the recognition of one's common humanity rather than making (positive or negative) self-judgments. Thus, it actually counters the tendencies toward narcissism and self-centeredness that may stem from attempts to maintain high self-esteem (Finn, 1990; McMillan et al., 1994), enhancing feelings of connection to others rather than setting oneself up in opposition to others. Those who approach their own experiences with compassion are more likely to have compassion for others, as it is not necessary to engage in downward social comparisons in order to think of the self as acceptable (which often means superior to others). Theoretically, it should also be easier and more effective to try to raise people's self-compassion than it is to raise their self-esteem, because self-compassion does not require that individuals adopt an unrealistic view of themselves. Research indicates that while people like to get positive feedback about themselves, they also like to receive feedback that is consistent with reality, or verifies their own beliefs about themselves (Swann, 1990, 1992). This is a primary reason why it is so difficult to raise others' self-esteem, especially through unrealistic praise - people don't buy it. Unrealistic praise is also dangerous in that it does not acknowledge that individuals may have patterns of behavior that need to be changed because these patterns are unproductive, unhealthy, or harmful (Damon, 1995). Encouraging people to have compassion for their failings and inadequacies, on the other hand, should allow for clearer recognition of those shortcomings, so that the need for self-verification is met. It should also allow people to rectify harmful patterns of behavior, not out of a need to improve their worth or status, but out of sense of caring and desire for the well-being of self and others.

\section{Self-Compassion and Psychological Functioning}

While research on the construct of self-compassion is in its early stages, ${ }^{3}$ there is good reason to believe that having compassion for oneself promotes mental well-being. 
Individuals who are self-compassionate should evidence greater psychological health than those with low levels of self-compassion, because the inevitable pain and sense of failure that is experienced by all individuals is not amplified and perpetuated through harsh self-condemnation (Blatt et al., 1982), feelings of isolation (Wood, Saltzberg, Neale, \& Stone, 1990) and over-identification with thoughts and emotions (Nolen-Hoeksema, 1991). This supportive attitude toward oneself should be associated with a variety of beneficial psychological outcomes, such as less depression, less anxiety, less neurotic perfectionism, and greater life satisfaction. Also, while the preceding discussion has focused on self-compassion in circumstances of pain or failure (since compassion is a response to an experience of suffering), selfcompassion should also be relevant in less aversive circumstances. Having selfcompassion implies that when possible, individuals will try to prevent themselves from experiencing suffering in the first place. Thus, self-compassion should give rise to proactive behaviors aimed at promoting or maintaining well-being - eating a healthy diet, for instance, or taking time off from work before becoming overly stressed.

Self-compassion is also likely to be related to other important psychological processes. For instance, it is likely that self-compassion is linked to behavioral motivation. Deci and Ryan (1995) suggested that "true self-esteem" (a sense of selfworth that is not contingent on set standards or expectations but is assumed as an inherent aspect of being) develops when an individual's actions reflect his or her authentic core self. In other words, true self-esteem emerges when behaviors are autonomous, self-determined and instrinsically rather than extrinsically motivated, so that actions are performed out of genuine interest rather than in response to an external threat or reward. Because individuals with high levels of self-compassion should have higher "true self-esteem," we would also expect that their behavior would tend to be more intrinsically motivated than the behavior of those with low levels of self-compassion. This motivational difference is likely to play itself out in many arenas, including academic learning. For instance, many educational psychologists have contrasted mastery-based academic goals (sometimes termed "learning goals" Dweck, 1986) with performance-based goals (Ames, 1992; Covington, 1992). When students have a mastery orientation toward learning, they are instrinsically motivated by the desire to develop new skills and understand new material, by curiosity and the joy of learning in and of itself. Students with performance-based goals, on the other hand, are motivated to succeed by the desire to enhance their sense of self-worth, or else they are motivated to defend their selfworth by avoiding failure (which sometimes means not trying in the first place). Because individuals with high self-compassion have a positive self-attitude that is not contingent on performance evaluations, they should tend to display mastery rather than performance goals in academic situations.

Another way in which self-compassion may be related to psychological functioning has to do with the clarity and accuracy of self-appraisals. Unlike high selfesteem, which has been associated with egoistic illusions and self-regulation failure (e.g., adopting inappropriate goals that are beyond performance capabilities; Baumeister et al., 1993), self-compassion should be linked to greater knowledge and clarity about one's limitations. This is because individuals do not have to hide their shortcomings from themselves in order to avoid harsh self-judgment. Moreover, having compassion for oneself means that the negative mood associated with suffering is partially transformed into a more positive affective state - that of compassion. Positive mood, in turn, has been associated with increased attention to and more careful, thorough processing of unflattering self-relevant information 
(Aspinwall, 1998). Thus, we would predict that more self-compassionate individuals should see themselves more clearly, which should also lead to more effective self regulation in terms of goal setting, risk taking, and so on.

Self-compassion may also be related to self-regulation in terms of coping with stress. As mentioned earlier, coping strategies have traditionally been classified as emotion-focused versus problem-focused (Endler \& Parker, 1990; Lazarus, 1993), with the latter being viewed in terms of emotional avoidance. However, recent work has tended to highlight proactive forms of "emotional approach" coping, which involve identifying, understanding, and expressing emotions in a psychologically adaptive way (Pennebaker, 1989, 1993; Salovey \& Mayer, 1990; Stanton et al., 1994). Thus, self-compassion should be related to higher levels of emotional approach rather than emotional avoidance coping. In addition, if self-compassionate individuals have greater self-clarity, they should be able to identify ways in which their own actions may be maintaining or exacerbating a stressful situation (for instance, by understanding that they have put themselves in a stressful situation and have the choice to leave it), enabling them to also take more "problem-focused" steps to alleviate stress.

\section{Individual and Group Differences in Self-Compassion}

An interesting question concerns the types of environments that foster or hinder the development of self-compassion within individuals. For instance, a child's early upbringing may impact whether or not that child will grow up to be a self-compassionate adult. Schafer $(1964,1968)$ proposed that an individual's ability to experience intra-psychic empathy-defined as the ability to pay adequate attention to one's emotions - is developed through the process of internalizing the empathic responses of the environment that one experienced as a child. Similarly, Stolorow, Brandchaft, and Atwood (1987) argued that the ability to recognize and attend to internal feeling states is linked to the empathy that children receive from their caregivers early on. This suggests that individuals who experienced warm, supportive relationships with their parents as children, and who perceived their parents as understanding and compassionate, should tend to have more self-compassion as adults. Conversely, it seems likely that those with cold or highly critical parents (or worse, who were psychologically, sexually, or physically abused as children), would tend to have less self-compassion (Brown, 1999).

Another intriguing question concerns whether or not differences in selfcompassion exist based on group variables such as age, sex or culture. Because females are generally considered to have a more interdependent sense of self (Cross \& Madson, 1997; Gilligan, 1988) and to be more empathic than males (Eisenberg \& Lennon, 1983; Zahn-Waxler, Cole, \& Barrett, 1991), one might expect women to be more self-compassionate than men. On the other hand, research evidence suggests that females tend to be more self-critical and to have more of ruminative coping style than males (Leadbeater, Kuperminc, Blatt, \& Hertzog, 1999; Nolen-Hoeksema, Larson, \& Grayson, 1999), suggesting that females may have lower levels of selfcompassion. A similar contradiction is faced when considering potential cultural differences in self-compassion. Because individuals from collectivist cultures, Asians in particular, have been described as having a more interdependent sense of self (Markus \& Kitayama, 1991; Shweder \& Bourne, 1984), and because they are likely to have had some prior exposure to Buddhist teachings on self-compassion through

cultural exposure, one might expect Asians to have more self-compassion than 
Westerners. However, it has also been shown that Asians tend to be more self-critical than Westerners (Kitayama \& Markus, 2000; Kitayama, Markus, Matsumoto, \& Norasakkunkit, 1997), which would suggest that Asians have less self-compassion. As it stands, it is unclear whether the development of self-compassion is helped or hindered by gender or cultural norms.

As to potential age-group differences in self-compassion, the developmental literature provides a more clear-cut basis for supposition: It is likely that adolescence is the period of life in which self-compassion is the lowest. The cognitive advances of adolescence - increased introspection, metacognition, self-reflection, and social perspective taking abilities (Keating, 1990) - also carry some liabilities. These newfound abilities mean that adolescents are continually evaluating themselves and comparing themselves to others as they attempt to establish their identity and place in the social hierarchy (Brown \& Lohr, 1987; Harter, 1990). Given the intense pressures faced by most adolescents - stress over academic performance, the need to be popular and "fit in" with the right peer crowd, body image problems (amplified due to puberty), dating, sex, etc.- these evaluations are often unfavorable (Harter, 1993; Simmons, Rosenberg, \& Rosenberg, 1973; Steinberg, 1999). Moreover, adolescence can be a period of extreme self-absorption. Such "adolescent egocentrism" (Elkind, 1967) may manifest as "the imaginary audience" - in which adolescents imagine that their appearance and behavior is the focus of everyone else's attention-or else as "the personal fable"-in which adolescents believe that their experiences are unique and that others can't possibly understand what they're going through. Adolescent egocentrism no doubt contributes to increased self-criticism, feelings of isolation, and over-identification with emotions, meaning that self-compassion is likely to be especially needed but especially lacking during this stage of life.

Because of the difficulties of the adolescent period, many well-meaning educators and psychologists have given a lot of attention to raising the self-esteem of adolescents (Palmer \& Froehner, 2000), girls in particular (American Association of University Women, 1994; Brown \& Gilligan, 1992; Pipher, 1994). Ironically, however, encouraging adolescents to have positive self-esteem may simply reinforce their tendency toward self-evaluation. If adolescents don't succeed in evaluating themselves positively, the inadvertent result may be an increase in negative evaluations of the self. Unfortunately, negative self-judgments are strongly implicated in the high incidence of depression found among adolescents, and in severe cases have also been linked to attempted suicide (Harter \& Marold, 1994; Laufer, 1995). A more effective intervention, therefore, may be to encourage adolescents to counter directly the agerelated tendencies that work against self-compassion, by teaching adolescents to be kind and understanding toward themselves, to realize that most teens go through similar problems, and to try to maintain a more balanced awareness of their emotional experiences.

\section{Conclusion}

The Buddhist concept of self-compassion, though relatively new in Western psychological circles, is worthy of further exploration due to its potential contribution to our understanding of self processes and mental health. Self-compassion offers a useful alternative to the more problematic construct of self-esteem, for the variety of reasons argued above. Moreover, the concept of mental well-being embodied by the self-compassion construct may offer an alternative to the over-emphasis on separation and individuation that has been criticized in many psychological 
definitions of mental health (Richardson et al., 1999). The idea behind selfcompassion is that, paradoxically, healthy and constructive self-attitudes stem in part from de-emphasizing the separate self, rather than merely building up and solidifying one's separate and unique identity. Self-compassion also represents a balanced integration between concern with oneself and concern with others, a state that researchers are increasingly recognizing as essential to optimal psychological functioning (Blatt, 1995). This balance does not stem from pitting concerns with oneself against concerns with others and finding some sort of compromise half-way point. Instead, it recognizes that all individuals should be treated with kindness and caring, and that a compassionate attitude toward oneself is needed to avoid falsely separating oneself from the rest of humanity.

Although it will require a great deal of empirical investigation, the possibilities of using the concept of self-compassion to aid those who suffer from negative selfattitudes are extremely promising. Encouraging the development of self-compassion should benefit individuals by helping them to counter destructive self-critical tendencies, acknowledge their interconnection with others, and deal with their emotions with greater clarity and equanimity. A culture shift which recognized the value of self-compassion could also benefit society, as it would encourage a kinder, less selfabsorbed, less isolated, and more emotionally functional populace.

\section{Notes}

1. It should be noted that the author is currently in the process of conducting research on self-compassion and its psychological correlates.

2. The one exception is a recent dissertation by Clark (1999) in which a pilot study was conducted to develop a scale of self-empathy using Jordan's conceptualizations. However, the content of the scale mainly focused on the two dimensions of validation of feelings (e.g., "I have a right to my opinion"; "I am entitled to my happy feelings"; "I cry for no reason") and recognition/expression of feelings (e.g., "When someone disappoints me, I express my feelings about it"; "I listen to my inner voice"; "I follow my gut in decision-making"). Thus, although the items for the self-empathy scale were partially based on feedback and suggestions from Jordan herself, it is unclear how much this particular operationalization of the self-empathy construct actually captures self-empathy as Jordan has described it, or how much it overlaps with the self-compassion construct as defined in this article.

3. The author has been developing a measure of self-compassion in an attempt to establish it as a valid psychological construct that has ramifications for psychological well-being. The goal has been to create a self-report scale that measures the three main dimensions of self-compassion: self-kindness, a sense of common humanity, and mindfulness.

\section{References}

Aberson, C. L., Healy, M., \& Romero, V. (2000). Ingroup bias and self-esteem: A metaanalysis. Personality \& Social Psychology Review, 4, 157-173.

Allport, G. (1954). The nature of prejudice. Cambridge, MA: Addison-Wesley.

American Association of University Women. (1994). How schools shortchange girls. Washington, DC: Author

Ames, C. (1992). Classrooms: Goals, structures, and student motivation. Journal of Educational Psychology, 84, 261-271.

Aspinwall, L. G. (1998). Rethinking the role of positive affect in self-regulation. Motivation and Emotion, 22, 1-32. 
Aspinwall, L. G., \& Taylor, S. E. (1993). Effects of social comparison direction, threat, and self-esteem on affect, self-evaluation, and expected success. Journal of Personality \& Social Psychology, 64, 708-722.

Bandura, A. (1990). Reflections on nonability determinants of competence. In R. J. Sternberg \& J. Kolligian, Jr. (Eds.), Competence considered (pp. 316-352). New Haven, CT: Yale University Press.

Baumeister, R. F., Heatherton, T. F., \& Tice, D. M. (1993). When ego threats lead to selfregulation failure: Negative consequences of high self-esteem. Journal of Personality and Social Psychology, 64, 141-156.

Baumeister, R. F., Smart, L., \& Boden, J. M. (1996). Relation of threatened egotism to violence and aggression: The dark side of high self-esteem. Psychological Review, 103, 533.

Beach, S. R., \& Tesser, A. (1995). Self-esteem and the extended self-evaluation maintenance model: The self in social context. In M. H. Kernis (Ed). Efficacy, agency, and self-esteem (pp. 145-170). New York: Plenum Press.

Bennett-Goleman, T. (2001). Emotional alchemy: How the mind can heal the heart. New York: Three Rivers Press.

Blatt, S. J. (1995). Representational structures in psychopathology. In D. Cicchetti \& S. Toth (Eds.), Rochester symposium on developmental psychopathology: Emotion, cognition, and representation, Vol. 6 (pp. 1-34). Rochester, NY: University of Rochester Press.

Blatt, S. J., Quinlan, D. M., Chevron, E. S., McDonald, C., \& Zuroff, D. (1982). Dependency and self-criticism: Psychological dimensions of depression. Journal of Consulting and Clinical Psychology, 50, 113-124.

Branden, N. (1969). The psychology of self-esteem. New York: Bantam

Bowlby, J. (1980). Attachment and loss: Vol. 3: Loss, separation, and depression. New York: Basic Books.

Brenner, E., \& Salovey, P. (1997). Emotion regulation during childhood: Developmental, interpersonal, and individual considerations. In P. Salovey \& D. Sluyter (Eds.), Emotional literacy and emotional development (pp. 168-192). New York: Basic Books.

Brown, B. (1999). Soul without shame: A guide to liberating yourself from the judge within. Boston: Shambala.

Brown, B., \& Lohr, M. J. (1987). Peer group affiliation and adolescent self-esteem: An integration of ego-identity and symbolic interaction theories. Journal of Personality and Social Psychology, 52, 47-55.

Brown, L. M., \& Gilligan, C. (1992). Meeting at the crossroads: Women's psychology and girls' development. Cambridge, MA: Harvard University Press.

Bugental, J. F. (1987). The art of the psychotherapist. New York: Norton.

Buunk, B. P. (1998). Social comparison and optimism about one's relational future: Order effects in social judgment. European Journal of Social Psychology, 28, 777-786.

Clark, C. A. (1999). The measurement of self-empathy based on the relational development model: A pilot study. Unpublished doctoral dissertation. Wright Institute.

Cooley, C. H. (1902). Human nature and the social order. New York: Scribner.

Coopersmith, S. (1967). The antecedents of self-esteem. San Francisco: W. H. Freeman.

Covington, M. V. (1992). Making the grade: A self-worth perspective on motivation and school reform. New York: Cambridge University Press.

Crocker, J., Thompson, L. L., McGraw, K. M., \& Ingerman, C. (1987). Downward comparison, prejudice, and evaluations of others: Effects of self-esteem and threat. Journal of Personality \& Social Psychology, 52, 907-916.

Cross, S. E., \& Madson, L. (1997). Models of the self: Self-construals and gender. Psychological Bulletin, 122, 5-37.

Damon, W. (1995). Greater expectations: Overcoming the culture of indulgence in America's homes and schools. New York: Free Press.

Deci, E. L., \& Ryan, R. M. (1995). Human autonomy: The basis for true self-esteem. In M. H. Kernis (Ed.), Efficacy, agency, and self-esteem (pp. 31-49). New York: Plenum. 
Dweck, C. S. (1986). Motivational processes affecting learning. American Psychologist, 41, 1040-1048.

Eisenberg, N., \& Lennon, R. (1983). Sex differences in empathy and related capacities. Psychological Bulletin, 9, 100-131.

Elkind, D. (1967). Egocentrism in adolescence. Child Development, 38, 1025-1034.

Ellis, A. (1973). Humanistic psychotherapy: The rational-emotive approach. New York: Julian Press.

Ellis, A., \& London, T. (1993). The case against self-esteem: How the self-esteem movement is damaging our children and culture. Chicago: Garfield Press.

Endler, N. S., \& Parker, J. D. (1990). Multidimensional assessment of coping: A critical evaluation. Journal of Personality and Social Psychology, 58, 844-854.

Enright, R. D., Freedman, S., \& Rique, J. (1998). The psychology of interpersonal forgiveness. In R. D. Enright \& J. North (Eds.), Exploring forgiveness, (pp. 46-62). Madison, WI: University of Wisconsin Press.

Epstein, M. D. (1995). Thoughts without a thinker. New York: Basic Books.

Fancher, R. (1995). Cultures of healing: Correcting the image of American mental health care. New York: Freeman.

Feather, N. T. (1994). Attitudes toward high achievers and reactions to their fall: Theory and research concerning tall poppies. In M. Zanna (Ed.), Advances in experimental social psychology (pp. 1-73). San Diego, CA: Academic Press.

Finn, C. E. (1990). Narcissus goes to school. Commentary, 89, 40-45.

Fredrickson, B. L. (2001). The role of positive emotions in positive psychology. American Psychologist, 56, 218-226.

Freud, S. (1958). Recommendations to physicians practicing psycho-analysis. In The Standard Edition of the Complete Psychological Works of Sigmund Freud, Vol. 12, (pp. 109-120). London: Hogarth.

Fromm, E. (1963). The art of loving. New York: Bantam Books.

Gilligan, C. (1988). Remapping the moral domain: New images of self in relationship. In C. Gilligan, J. Ward, \& J. Taylor (Eds.), Mapping the moral domain (pp. 3-19). Cambridge, MA: Harvard University Press.

Goldstein, A. P., \& Michaels, G. Y. (1985). Empathy: Development, training, and consequences. Hillsdale, NJ: Erlbaum.

Goldstein, J., \& Kornfield, J. (1987). Seeking the heart of wisdom: The path of insight meditation. Boston: Shambhala.

Gunaratana, V. H. (1993). Mindfulness in plain English. Somerville, MA: Wisdom Publications.

Hanh, T. N. (1976). The miracle of mindfulness. Boston: Beacon Press.

Hanh, T. N. (1997). Teachings on love. Berkeley, CA: Parallax Press.

Harter, S. (1990). Identity and self-development. In S. Feldman \& G. Elliot (Eds.), At the threshold: The developing adolescent (pp. 352-387). Cambridge, MA: Harvard University Press.

Harter, S. (1993). Visions of self: Beyond the me in the mirror. In J. E. Jacobs, (Ed.), Nebraska symposium on motivation, 1992: Developmental perspectives on motivation, 40. (pp. 99144). Lincoln, NE: University of Nebraska Press.

Harter, S. (1999). The construction of the self: A developmental perspective. New York: Guilford Press.

Harter, S., \& Marold, D., (1994). Psychosocial risk factors contributing to adolescent suicidal ideation. In G. G. Noam \& S. Borst (Eds.), Children, youth, and suicide: Developmental perspectives (pp. 71-91). San Francisco: Jossey-Bass.

Hayes, S. C., Strosahl, K. D., \& Wilson, K. G. (1999). Acceptance and commitment therapy: An experiential approach to behavior change. New York: Guilford.

Hayes, S. C., Wilson, K. G., Gifford, E. V., Follette, V. M., \& Strosahl, K. (1996). Experiential avoidance and behavioral disorders: A functional dimensional approach to diagnosis and treatment. Journal of Consulting and Clinical Psychology, 64, 1152-1168. 
Hewitt, J. P. (1998). The myth of self-esteem: Finding happiness and solving problems in America. New York: St. Martin's Press.

Horney, K. (1950). Neurosis and human growth: The struggle toward self-realization. New York: Norton.

James, W. (1890). Principles of psychology. Chicago: Encyclopedia Britannica.

Jopling, D. A. (2000). Self-knowledge and the self. New York: Routledge.

Jordan, J. V. (1989). Relational development: Therapeutic implications of empathy and shame. Work in Progress, No. 39. Wellesley, MA: Stone Center Working Paper Series.

Jordan, J. V. (1991a). Empathy and self-boundaries. In J. V. Jordan, A. G. Kaplan, J. B. Miller, I. P. Stiver, \& J. L. Surrey (Eds.), Women's growth in connection: Writings from the Stone Center (pp. 67-80). New York: Guilford.

Jordan, J. V. (1991b). Empathy, mutuality and therapeutic change: Clinical implications of a relational model. In J. V. Jordan et al. (Eds.), Women's growth in connection: Writings from the Stone Center (pp. 283-290). New York: Guilford.

Jordan, J. V. (Ed). (1997). Women's growth in diversity: More writings from the Stone Center. New York: Guilford.

Jordan, J. V., Kaplan, A. G., Miller, J. B., Stiver, I. P., \& Surrey, J. L. (Eds.). (1991). Women's growth in connection: Writings from the Stone Center. New York: Guilford.

Kabat-Zinn, J. (1994). Wherever you go there you are. New York: Hyperion.

Kabat-Zinn, J., \& Chapman-Waldrop, A. (1988). Compliance with an outpatient stress reduction program: Rates and predictors of program completion. Journal of Behavioral Medicine, 11, 333-352.

Kabat-Zinn, J., Massion, A. O., Kristeller, J., \& Peterson, L. G. (1992). Effectiveness of a meditation-based stress reduction program in the treatment of anxiety disorders. American Journal of Psychiatry, 149, 936-943.

Keating, D. (1990). Adolescent thinking. In S. Feldman \& G. Elliot (Eds.), At the threshold: The developing adolescent (pp. 54-89). Cambridge, MA: Harvard University Press.

Kitayama, S., \& Markus, H. R. (2000). The pursuit of happiness and the realization of sympathy: Cultural patterns of self, social relations, and well-being. In E. Diener \& E. M. Suh (Eds.), Culture and subjective well-being (pp. 113-161). Cambridge, MA: MIT Press.

Kitayama, S., Markus, H. R., Matsumoto, H., \& Norasakkunkit, V. (1997). Individual and collective processes in the construction of the self: Self-enhancement in the United States and self-criticism in Japan. Journal of Personality \& Social Psychology, 72, 1245-1267.

Kornfield, J. (1993). A path with heart. New York: Bantam Books.

Langer, E., J. (1989). Mindfulness. Reading, MA: Addison-Wesley.

Laufer, M. E. (1995). Depression and self-hatred. In M Laufer (Ed.), The suicidal adolescent. (pp. 21-27). Madison, CT: International Universities Press.

Lazarus, R. S. (1993). From psychological stress to the emotions: A history of a changing outlook. Annual Review of Psychology, 44, 1-21.

Leadbeater, B. J., Kuperminc, G. P., Blatt, S. J., \& Hertzog, C. (1999). A multivariate model of gender differences in adolescents' internalizing and externalizing problems. Developmental Psychology, 35, 1268-1282.

McMillan, J. H., Singh, J., \& Simonetta, L. G. (1994). The tyranny of self-oriented self-esteem. Educational Horizons, Sp, 141-145.

Markus, H. R., \& Kitayama, S. (1991). Culture and the self: Implications for cognition, emotion, and motivation. Psychological Review, 98, 224-253.

Martin, J. R. (1997). Mindfulness: A proposed common factor. Journal of Psychotherapy Integration, 7, 291-312.

Maslow, A. H. (1954). Motivation and personality. New York: Harper.

Maslow, A. H. (1968). Toward a psychology of being. New York: Van Nostrand.

McKay, M., \& Fanning, P. (1987). Self-esteem. Oakland, CA: New Harbinger.

Mead, G. H. (1934). Mind, self, and society. Chicago: University of Chicago Press.

Miller, D. T. (1999). The norm of self-interest. American Psychologist, 54, 1053-1060. 
Molino, A. (Ed). (1998). The couch and the tree: Dialogues in psychoanalysis and Buddhism. New York: North Point Press.

Nolen-Hoeksema, S. (1991). Responses to depression and their effects on the duration of depressive episodes. Journal of Abnormal Psychology, 100, 569-582.

Nolen-Hoeksema, S., Larson, J., \& Grayson, C. (1999). Explaining the gender difference in depressive symptoms. Journal of Personality and Social Psychology, 77, 1061-1072.

Nisker, W. (1998). Buddha's nature. New York: Bantam.

Palmer, P., \& Froehner, M. A. (2000). Teen esteem: A self-direction manual for young adults. San Luis Obispo, CA: Impact Publishers.

Pearson, E. M., \& Podeschi, R. L. (1999). Humanism and individualism: Maslow and his critics. Adult Education Quarterly, 50, 41-55.

Pennebaker, J. W. (1989). Confession, inhibition, and disease. In L. Berkowitz (Eds.), Advances in experimental social psychology (pp. 211-244). New York: Academic Press.

Pennebaker, J. W (1993). Putting stress into words: Health, linguistic, and therapeutic implications. Behaviour Research and Therapy, 31, 539-548.

Pipher, M. (1994). Reviving Ophelia: Saving the selves of adolescent girls. New York: Putnam.

Reich, W. (1949). Character analysis. New York: Orgone Institute Press.

Richardson, F., Fowers, B. \& Guignon, C. (1999). Re-envisioning psychology: Moral dimensions of theory and practice. San Francisco, CA: Jossey-Bass.

Rogers, C. R. (1961). On becoming a person. Boston: Houghton Mifflin.

Rogers, C. R., \& Stevens, B. (1967). Person to person: The problem of being human. Moab, UT: Real People Press.

Rosenberg, L. (1999). Breath by breath: The liberating practice of insight meditation. Boston: Shambala.

Rosenberg, M. (1979). Conceiving the self. New York: Basic Books.

Rosenberg, M. B. (2000). Nonviolent communication: A language of compassion. Encinitas, CA: PuddleDancer Press.

Rubin, J. B. (1996). Psychotherapy and Buddhism: Toward an integration. New York: Plenum.

Rubin, T. I. (1975). Compassion and self-hate: An alternative to despair. New York: D. McKay.

Rutledge, T. (1997). The self-forgiveness handbook: A practical and empowering guide. Oakland, CA: New Harbinger Publications.

Safran, J. D., \& Segal, Z. V. (1990). Interpersonal process in cognitive therapy. Northvale, NJ: Jason Aronson.

Salovey, P., \& Mayer, J. D. (1990). Emotional intelligence. Imagination, Cognition \& Personality, 9, 185-211.

Salzberg, S. (1997). Lovingkindness: The revolutionary art of happiness. Boston: Shambala.

Schafer, R. (1964). The clinical analysis of affects. Journal of the American Psychoanalytic Association, 12, 275-299.

Schafer, R. (1968). Aspects of internalization. New York: International Universities Press.

Scheff, T. J. (1981). The distancing of emotion in psychotherapy. Psychotherapy: Theory, Research \& Practice, 18, 46-53.

Sedikides, C. (1993). Assessment, enhancement, and verification determinants of the selfevaluation process. Journal of Personality and Social Psychology, 65, 317-338.

Seligman, M. E. (1995). The optimistic child. Boston: Houghton Mifflin.

Shweder, R. A., \& Bourne, E. J. (1984). Does the concept of person vary cross-culturally? In R. A. Shweder \& R. A. LeVine (Eds.), Culture theory: Essays on mind, self, and emotion (pp. 158-199). Cambridge, UK: Cambridge University Press.

Simmons, R., Rosenberg, F., \& Rosenberg, M. (1973). Disturbance in the self-image at adolescence. American Sociological Review, 38, 553-568.

Snyder, M. (1994). The development of social intelligence in psychotherapy. Journal of Humanistic Psychology, 34, 84-108.

Stanton, A. L., Danoff-Burg, S., Cameron, C. L., \& Ellis, A. P. (1994). Coping through emotional approach: Problems of conceptualization and confounding. Journal of Personality and Social Psychology, 66, 350-362. 
Stanton, A. L., Kirk, S. B., Cameron, C. L., \& Dannoff-Burg, S. (2000). Coping through emotional approach: Scale construction and validation. Journal of Personality and Social Psychology, 78, 1150-1169.

Steinberg, L. (1999). Adolescence (5th ed.). Boston: McGraw-Hill.

Steinem, G. (1992). Revolution from within: A book of self-esteem. Boston: Little-Brown.

Stolorow, R. D., Brandchaft, B. E., \& Atwood, G. E. (1987). Psychoanalytic treatment: An intersubjective approach. Hillsdale, NJ: The Analytic Press.

Suls, J., \& Wills, T. A. (1991). Social comparison: Contemporary theory and research. Hillsdale, NJ: Erlbaum.

Swann, W. B. (1990). To be adored or to be known?: The interplay of self-enhancement and self-verification. In E. T. Higgins \& R. M. Sorrento (Eds.), Handbook of motivation and cognition: Foundations of social behavior, Vol. 2 (pp. 408-448). New York: Guilford.

Swann, W. B. (1992). Seeking "truth," finding despair: Some unhappy consequences of a negative self-concept. Current Directions in Psychological Science, 1, 15-18.

Swann, W. B. (1996). Self-traps: The elusive quest for higher self-esteem. New York: Freeman.

Taylor, S. E., \& Brown, J. D. (1988). Illusion and well-being: A social psychological perspective on mental health. Psychological Bulletin, 103, 193-210.

Teasdale, J. D., Segal, Z. V., Williams, J. M., Ridgeway, V. A., Soulsby, J. M., \& Lau, M. A. (2000). Prevention of relapse/recurrence in major depression by mindfulness-based cognitive therapy. Journal of Consulting \& Clinical Psychology, 68, 615-623.

Thompson, R. A. (1994). Emotion regulation: A theme in search of definition. Monographs of the Society for Research in Child Development, 59, 25-52.

Turiel, E. (1983). Domains and categories in social cognitive development. In W. Overton (Ed.), The relationship between social and cognitive development. Hillsdale, NJ: Erlbaum.

Turner, J. C., Hogg, M. A., Oakes, P. J., Reicher, S. D., \& Wetherell, M. S. (1987). Rediscovering the social group: A self-categorization theory. Oxford, UK: Basil Blackwell.

Wallace, B. A. (1999). Boundless heart: The four immeasurables. Ithaca, NY: Snow Lion Publications.

Watson, G., Batchelor, S., \& Claxton, G. (Eds.). (1999). The psychology of awakening. Boston: Red Wheel/Weiser.

Wispe, L. (1991). The psychology of sympathy. New York: Plenum.

Wood, J. V., Saltzberg, J. A., Neale, J. M., \& Stone, A. (1990). Self-focused attention, coping responses, and distressed mood in everyday life. Journal of Personality \& Social Psychology, 58, 1027-1036.

Zahn-Waxler, C., Cole, P. M., \& Barrett, K. C. (1991). Guilt and empathy: Sex differences and implications for the development of depression. In J. Garber \& K. A. Dodge (Eds.), The development of emotion regulation and dysregulation (pp. 243-272). New York: Cambridge University Press. 
Copyright $@ 2003$ EBSCO Publishing 